\title{
EFFECT OF TWO STUNNING METHODS ON POSTMORTEM MUSCLE PH AND MEAT QUALITY OF COMMON CARP (CYPRINUS CARPIO L.)
}

\author{
A. H. DASKALOVA \& A. I. PAVLOV \\ Department of Food Hygiene, Technology and Control, Veterinary \\ Legislation and Management, Faculty of Veterinary Medicine, \\ Trakia University, Stara Zagora, Bulgaria
}

\section{Summary}

Daskalova, A. H. \& A. I. Pavlov, 2015. Effect of two stunning methods on postmortem muscle $\mathrm{pH}$ and meat quality of common carp (Cyprinus carpio L.). Bulg. J. Vet. Med., 18, No $1,83-90$.

Percussive and electrical stunning are the most promising methods in terms of rendering fish unconscious prior to slaughter. The aim of this study was to determine the effect of these two stunning methods on postmortem muscle changes and meat quality of common carps. The experimental fish were stunned either by percussion (Group 1) or by electrical current application (Group 2), both followed by immediate decapitation. Muscle $\mathrm{pH}$ was measured at different time intervals to assess the postmortem metabolic changes, whereas meat colour, drip loss and water activity were used as quality parameters. The fish in Group 1 showed slightly accelerated postmortem muscle metabolism, higher redness $\left(\mathrm{a}^{*}\right)$ and yellowness $\left(\mathrm{b}^{*}\right)$ colour values and lower water activity. Percentage of drip loss after 4 days of storage at $4{ }^{\circ} \mathrm{C}$ did not differ significantly between the two groups. Based on the obtained results we concluded that both tested stunning methods were not associated with high levels of stress and significant detrimental effect on the meat quality of common carps.

Key words: fish stunning, meat quality, muscle $\mathrm{pH}$, slaughter, stress

\section{INTRODUCTION}

In the recent years, there has been growing scientific and commercial interest in the area of animal welfare, especially with regard to the development of humane stunning and slaughter methods. Until now, the EU legislation has not provided specific requirements in terms of the procedures for stunning and killing fish. Nevertheless, these procedures must be based on the key principle, i.e. avoiding pain and suffering (Anonymous, 2009a). This is the reason why a number of recent studies have been conducted to establish effective stunning/slaughter methods for fish (Erikson et al., 2006; Lambooij et al., 2010; Llonch et al., 2012) and to assess their impact on fish meat quality (Kiessling et 
Effect of two stunning methods on postmortem muscle $\mathrm{pH}$ and meat quality of common carp ...

al., 2004; Roth et al., 2007; Rahmanifarah et al., 2011).

It should be noted that some of the commonly used methods for stunning and killing fish, such as $\mathrm{CO}_{2}$ narcosis, asphyxia, thermal shock, live exsanguination, etc., may be too slow and aversive (Anonymous, 2004). Moreover, the inappropriate preslaughter and slaughter procedures are usually followed by extreme stress reaction and increased muscle activity at the time of killing (Rahmanifarah et al., 2010; Erikson, 2011). As a result, the stressed fish may exhibit various changes in postmortem muscle metabolism, such as enhanced anaerobic glycolysis, lower initial and ultimate $\mathrm{pH}$, rapid rigor mortis onset (Wilkinson et al., 2008; Rahmanifarah et al., 2011) and accelerated proteolytic activity (Bahuaud et al., 2010). All these metabolic changes can lead to impaired meat quality, often manifested by softer texture, reduced waterholding capacity (higher drip loss), lighter colour, higher gaping scores, etc. (Robb et al., 2000; Kiessling et al., 2004; Bosworth et al., 2007).

According to EFSA opinion (Anonymous, 2009b) further research is needed to establish proper stunning/killing procedures for common carps, with focus on the potential effectiveness of percussive and electrical stunning. This was the main reason why our study was aimed at evaluating the impact of percussive and electrical stunning, both followed by decapitation, on postmortem muscle changes and some meat quality parameters of common carps (Cyprinus carpio L.). Moreover, we aimed to evaluate possible negative effects of electrical stunning (using low amperage electric current) on meat quality as compared to the percussive method, which is commonly used as a control method.

\section{MATERIALS AND METHODS}

\section{Fish and sampling}

A batch of 20 market sized carps (average body weight $1482.52 \pm 215.63 \mathrm{~g}$ ) was purchased from a commercial fish farm (Nikolaevo, Bulgaria). Immediately after arrival the fish were separated in two groups: Group $1(\mathrm{n}=10)$ and Group 2 $(n=10)$ and placed in two tanks with $800 \mathrm{~L}$ tap water (water temperature $17.2 \pm 0.9^{\circ} \mathrm{C}$; $\mathrm{pH} 7.13 \pm 0.02$ ) and constant aeration (dissolved oxygen concentration $3.48 \pm 0.32$ mg. $\left.\mathrm{L}^{-1}\right)$. The carps were kept for one week at these conditions and then, the two groups were stunned by two different methods. The experimental design was approved by the Ethics and Animal Welfare Committee at Trakia University, Stara Zagora.

The fish in Group 1 were killed by a percussive blow on the head with a $300 \mathrm{~g}$ hammer, followed by decapitation. The fish in Group 2 were stunned electrically using a device consisting of a capacitor (condenser) and two copper plates (electrodes), kindly provided by Dr Atanasov (Department of Animal Husbandry, Faculty of Veterinary Medicine, Stara Zagora) and used for immobilisation of fish (unpublished data). The carps were transferred to a smaller water container and the electrodes of the stunner were immersed into the water and placed bilaterally on the cranium. Each fish was subjected to an electrical current (DC) with high voltage $(\sim 300 \mathrm{~V})$, low capacitance $(47 \mu \mathrm{F})$ and low amperage $(4.7 \mathrm{~mA})$ for $3 \mathrm{~s}$ and then immediately decapitated. If some of the fish were not stunned adequately after the first current application, they were exposed to the current for the second time to obtain an epileptic-like seizure which, as described by Robb et al. (2002), is characterised by a strong muscle spasm along 
the body, open mouth, stretched fins, followed by relaxation and separate muscle twitches.

Four muscle samples were obtained from each experimental fish, as followed: 1) For $\mathrm{pH}$ determination $-\mathrm{a}$ part of the dorsal muscle $(12 \times 3 \times 2 \mathrm{~cm}) ; 2)$ For meat color - a white muscle piece $(3 \times 2 \times 1 \mathrm{~cm})$ from the upper part of the fillet; 3 ) For water activity $\left(\mathrm{a}_{\mathrm{w}}\right)-2$ white muscle samples (approximately $10 \mathrm{~g}$ ); 4) For drip loss - a part of the dorsal muscle $(10 \times 2 \times 1 \mathrm{~cm})$.

\section{Physicochemical analyses}

Muscle $\mathrm{pH}$ was measured at $0,3,6,12$, 24, 48 and $72 \mathrm{~h}$ using Consort C532 pH meter (Consort nv, Turnhout, Belgium) by inserting a penetration electrode directly into the muscle sample. Between measurements the samples were kept in a refrigerator at $4{ }^{\circ} \mathrm{C}$.

Meat colour values $\left(\mathrm{L}^{*}, \mathrm{a}^{*}\right.$ and $\left.\mathrm{b}^{*}\right)$ were estimated by Lovibond SP60 spectrophotometer (X-Rite Inc., Grandville, Michigan, USA). The CIE L*a*b* color space included the following colour coordinates: lightness $\left(\mathrm{L}^{*}\right)$ - ranging from 0 (black) to 100 (white); red/green coordinate $\left(a^{*}\right)$ : $+a^{*}$ indicating redness and $-a^{*}$ indicating greenness; yellow/blue coordinate $\left(b^{*}\right)$ : $+b^{*}$ indicating yellowness and $-b^{*}$ indicating blueness (EN 15886:2010).

For measuring water activity level, the obtained white muscle samples were cut into small pieces and put into the probe holder of HygroLab water activity analyzer (Rotronic AG, Bassersdorf, Switzerland). These analyses were performed at days 0 and 4 . Between the measurements the muscle samples were wrapped in plastic bags and kept in a refrigerator at $4{ }^{\circ} \mathrm{C}$.

Drip loss (\%) was estimated as described by Roth et al. (2006). The obtained muscle samples were weighed $\left(\mathrm{W}_{0}\right)$, wrapped in aluminium foil and put in a refrigerator at $4{ }^{\circ} \mathrm{C}$. After 4 days of storage, the samples were unwrapped, cleaned of the excess fluid and weighed again $\left(\mathrm{W}_{1}\right)$. The drip loss was calculated using the following formula: $\%$ drip loss $=$ $\left[\left(\mathrm{W}_{0}-\mathrm{W}_{1}\right) / \mathrm{W}_{0}\right] \times 100$.

Dissolved oxygen concentration and water temperature were measured using a portable Multi meter 340i/SET (WTW, Germany) by immersing the probe directly in the water sample. Water $\mathrm{pH}$ was estimated on Sartorius Basic Meter PB-11 (Sartorius AG, Germany).

\section{Statistical analysis}

The results were presented as mean $\pm \mathrm{SD}$. All quantitative parameters were analysed using Student's $t$ test (Microsoft Excel 2010).

\section{RESULTS}

Results revealed clear differences in postmortem muscle metabolism and some of the tested quality parameters of the fish in the two experimental groups.

Muscle $p H$

Immediately after death the fish stunned by percussion (Group 1) had $\mathrm{pH}$ about 7, which decreased significantly $(\mathrm{P}<0.001)$ at hour 3 and continued to drop until the $12^{\text {th }}$ hour when $\mathrm{pH}$ reached its ultimate level of $6.49 \pm 0.10$. A significant increase $(\mathrm{P}<0.001)$ was observed at hour 24 , followed by a decrease $(\mathrm{P}<0.05)$ at hour 48 . At the last time interval $(72 \mathrm{~h}) \mathrm{pH}$ raised $(\mathrm{P}<0.001)$ as compared to the $48^{\text {th }}$ hour but remained lower $(\mathrm{P}<0.001)$ as compared to the initial values (Fig. 1).

The electrically stunned carps (Group 2) had significantly lower $(\mathrm{P}<0.01)$ initial meat $\mathrm{pH}$ as compared to Group 1, which decreased $(\mathrm{P}<0.001)$ by the $3^{\text {rd }}$ hour and persisted almost unchanged up to post- 


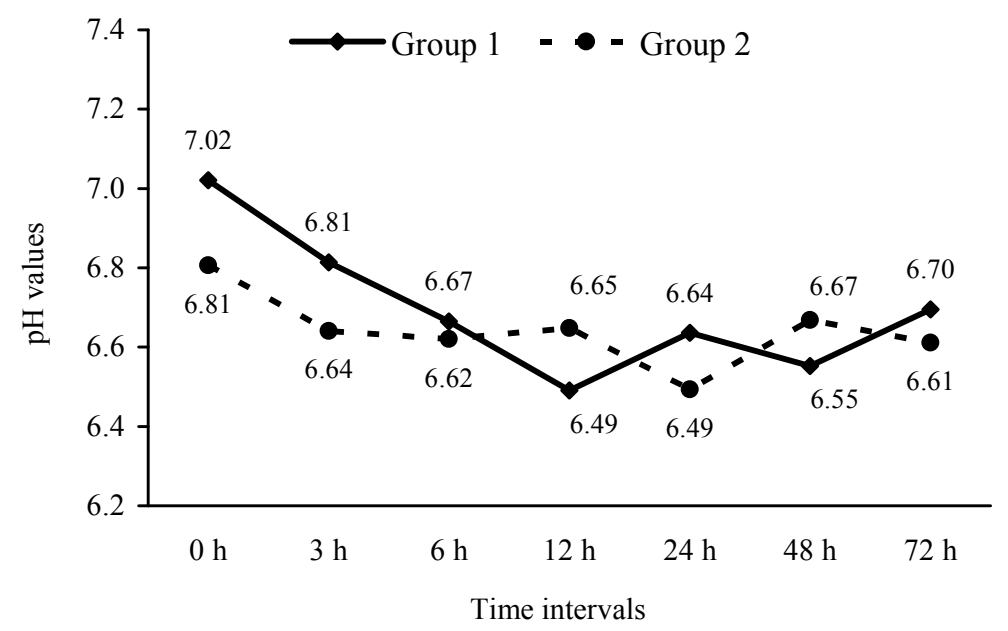

Fig. 1. Postmortem muscle $\mathrm{pH}$ of carps stunned by percussion (Group 1) or by $3 \mathrm{~s}$ exposure to an electrical current (Group 2), both followed by immediate decapitation. The data labels at each time point show the mean $\mathrm{pH}$ values.

mortem hour 12. After that, $\mathrm{pH}$ started to drop again and at $24 \mathrm{~h}$ reached its ultimate level of $6.49 \pm 0.12$. At hour $48 \mathrm{pH}$ values increased $(\mathrm{P}<0.01)$ and remained unchanged up to the end of the study. At hour 72 , meat $\mathrm{pH}$ of the electrically stunned carps was still lower $(\mathrm{P}<0.01)$ than the initial levels, and similar to that of fish killed by percussion (Fig. 1).

\section{Meat colour, drip loss and water activity}

At day 0 , the lightness $\left(\mathrm{L}^{*}\right)$ values did not differ significantly between the two experimental groups. At the same time, the muscle samples obtained from the carps in Group 1 showed higher redness $\left(\mathrm{a}^{*}\right)$ $(\mathrm{P}<0.001)$ and yellowness $\left(\mathrm{b}^{*}\right) \quad(\mathrm{P}<0.05)$ values than those from Group 2 (Table 1). Similar differences between groups were observed after 4 days of storage. Furthermore, by day $4 \mathrm{~L}^{*}$ decreased considerably $(\mathrm{P}<0.001)$ in both groups as compared to the initial values and in addition, the electrically stunned carps showed lower $b^{*}$ values $(\mathrm{P}<0.001)$.
The drip loss percentage of the muscle samples after 4 days of storage at $4^{\circ} \mathrm{C}$ did not differ significantly between the two groups (Table 1).

The results from water activity analyses showed that the muscles of the fish stunned by percussion had lower $\mathrm{a}_{\mathrm{w}}$ at both days $0(\mathrm{P}<0.01)$ and $4(\mathrm{P}<0.001)$ as compared to the carps stunned by electricity. The storage of the samples for 4 days at $4{ }^{\circ} \mathrm{C}$ did not lead to any significant changes in the water activity level in either group (Table 1).

\section{DISCUSSION}

Percussion and electricity are the two stunning methods that have proven to be effective in terms of humane killing of fish (Lambooij et al., 2010; Erikson et al., 2012). Whereas percussion has been used as a control method by some authors (Rahmanifarah et al., 2011), electrical stunning still poses certain challenges in terms of quality (Roth et al., 2003). Our aim was to 
Table 1. Meat colour values ( $\left.L^{*}, a^{*}, b^{*}\right)$, drip loss (\%) and water activity of carps stunned either by percussion (Group 1) or by $3 \mathrm{~s}$ exposure to an electrical current (Group 2), both followed by immediate decapitation. Data are presented as mean $\pm \mathrm{SD}$.

\begin{tabular}{|c|c|c|c|c|c|c|}
\hline & \multirow{2}{*}{$\begin{array}{c}\text { Time } \\
\text { interval }\end{array}$} & \multicolumn{3}{|c|}{ Colour coordinates } & \multirow{2}{*}{$\begin{array}{c}\text { Drip loss, } \\
\%\end{array}$} & \multirow[t]{2}{*}{ Water activity } \\
\hline & & $\mathrm{L}^{*}$ & $a^{*}$ & $b^{*}$ & & \\
\hline \multirow{2}{*}{ Group 1} & day 0 & $45.64 \pm 1.96^{\mathrm{ax}}$ & $3.18 \pm 0.30^{\mathrm{ax}}$ & $6.03 \pm 0.90^{\mathrm{ax}}$ & - & $0.946 \pm 0.006^{\mathrm{ax}}$ \\
\hline & day 4 & $44.49 \pm 2.02^{\mathrm{cy}}$ & $3.12 \pm 0.32^{\mathrm{cx}}$ & $5.81 \pm 1.19^{\mathrm{cx}}$ & $1.68 \pm 0.32^{\mathrm{c}}$ & $0.944 \pm 0.005^{\mathrm{cx}}$ \\
\hline \multirow{2}{*}{ Group 2} & day 0 & $45.15 \pm 0.79^{\mathrm{ax}}$ & $2.72 \pm 0.20^{\mathrm{bx}}$ & $5.12 \pm 0.19^{\mathrm{bx}}$ & - & $0.960 \pm 0.011^{\mathrm{bx}}$ \\
\hline & day 4 & $43.25 \pm 0.80^{\text {cy }}$ & $2.73 \pm 0.37^{\mathrm{dx}}$ & $4.02 \pm 0.41^{\mathrm{dy}}$ & $1.46 \pm 0.27^{\mathrm{c}}$ & $0.961 \pm 0.003^{\mathrm{dx}}$ \\
\hline
\end{tabular}

Statistically significant differences $(\mathrm{P}<0.05)$ between the groups and time intervals for each of the tested parameters are denoted by different letters $(\mathrm{a}-\mathrm{b}$ indicate differences between groups at day 0 ; $\mathrm{c}-\mathrm{d}$ indicate differences between groups at day $4 ; \mathrm{x}-\mathrm{y}$ indicate differences between day 0 and day 4 within the same group).

assess the differences in postmortem muscle metabolism and some meat quality parameters of carps stunned either by percussion or by applying electricity.

The fish stunned electrically showed accelerated anaerobic muscle metabolism immediately after death as this group of fish had lower initial muscle $\mathrm{pH}$ in comparison to the carps stunned by percussion. Similar findings were observed by Roth et al. (2007) in electrically stimulated turbot. Furthermore, when the fish is subjected to extremely stressful procedures before and/or at the time of slaughter, postmortem muscle $\mathrm{pH}$ is usually characterized by low initial values, rapid decline in time (reaching ultimate values between 3 and $9 \mathrm{~h}$ after death) and considerably lower ultimate levels (Wilkinson et al., 2008; Rahmanifarah et al., 2011). Despite the lower initial $\mathrm{pH}$ values, our electrically stunned fish showed slower $\mathrm{pH}$ decrease in time, no significant differences in the ultimate $\mathrm{pH}$ values and similar $\mathrm{pH}$ levels at the final point as compared to Group 1. Therefore, as judged by the changes in postmortem $\mathrm{pH}$, we may conclude that both stunning/killing meth- ods were not associated with unacceptable levels of stress. However, electrical stunning showed slight superiority judging by the slower and steadier course of the postmortem metabolic processes. At this point, we have no good explanation for the $\mathrm{pH}$ fluctuations detected in Group 1, but similar findings have been previously observed in Senegal sole and barramundi (Ribas et al., 2007; Wilkinson et al., 2008). These fluctuations though, were not of great importance for the conclusions made in this study, as they did not affect the interval between the initial and the ultimate $\mathrm{pH}$ values.

It has been found that the strong postmortem $\mathrm{pH}$ decline is a key factor for the development of so-called "pale, soft, exudative" (PSE) meat in turkeys, characterised by lighter colour and reduced waterholding capacity (Pietrzak et al., 1997). As mentioned above, comparable changes can be observed in stressed fish. In this line, as our experimental groups of fish had very similar ultimate $\mathrm{pH}$ (which was not extremely low), it was not surprising that they showed no significantly different levels of drip loss and $L^{*}$ values. On the 
Effect of two stunning methods on postmortem muscle $\mathrm{pH}$ and meat quality of common carp ...

other hand, the musculature of the fish from Group 1 had higher $a^{*}$ and higher $b^{*}$ values both at days 0 and 4 as compared to Group 2. Contrary to these findings, Roth et al. (2006) reported higher a* and $\mathrm{b}^{*}$ values in Atlantic salmon (Salmo salar) killed by a sharp blow on the head and then exercised electrically for $2 \mathrm{~min}$ in comparison to salmon killed by the same method but without subsequent electrical stimulation. We may hypothesise that the reason for this discrepancy is the enhanced anaerobic muscle metabolism in the electrically stimulated salmon (earlier rigor mortis onset) which is more similar to the postmortem changes in our carps stunned by percussion (faster $\mathrm{pH}$ decrease).

Interestingly, the musculature of our electrically stunned carps showed significantly higher water activity levels as compared to the fish stunned by percussion. Water activity $\left(a_{\mathrm{w}}\right)$ expresses the vapour pressure generated by the unbound water in foods. Borba et al. (2013) observed no effect of the rearing system on the water activity of broiler breast muscles despite the differences found in $\mathrm{pH}$ and meat redness $\left(\mathrm{a}^{*}\right)$. Until now, no direct relation has been discovered between stress or electrical current application and water activity of the obtained meat. As water activity is one of the most important factors affecting bacterial growth (Troller, 1971) and food stability (Mathlouthi, 2001), further research is needed to determine whether its level in our study was certainly influenced by the stunning method.

We conclude that both stunning/killing methods used in this study do not cause unacceptable levels of stress, as well as do not have any considerable adverse effect on the quality of the obtained meat. However, electrical stunning demonstrates slight superiority as judged by the slower postmortem $\mathrm{pH}$ decline. Therefore, electrical stunning, after some improvements of the electrical device eliminating the need of repeated current application, could be a suitable method for stunning fish in the commercial practice.

\section{ACKNOWLEDGEMENTS}

The authors would like to thank Assistant Prof. Aleksandar Atanasov for providing the electrical stunning device used in this study. Financial and technical support was supplied by the Faculty of Veterinary Medicine, Trakia University, Stara Zagora.

\section{REFERENCES}

Anonymous, 2004. Opinion of the Scientific Panel on Animal Health and Welfare on a request from the Commission related to welfare aspects of the main systems of stunning and killing the main commercial species of animals. The EFSA Journal, $\mathbf{4 5}$, 1-29. http://www.efsa.europa.eu/fr/scdocs/ doc/45.pdf (6 July 2004, date last assessed).

Anonymous, 2009a. Council Regulation (EC) No $1099 / 2009$ of 24 September 2009 on the protection of animals at the time of killing. European Community Official Journal, L303, 1-30.

Anonymous, 2009b. Scientific Opinion of the Panel on Animal Health and Welfare on a request from the European Commission on Species-specific welfare aspects of the main systems of stunning and killing of farmed carp. The EFSA Journal, 1013, 137.

Bahuaud, D., T. Mørkøre, T.-K. Østbye, E. Veiseth-Kent, M. S. Thomassen \& R. Ofstad, 2010. Muscle structure responses and lysosomal cathepsins B and L in farmed Atlantic salmon (Salmo salar L.) pre- and post-rigor fillets exposed to short and long-term crowding stress. Food Chemistry, 118, 602-615. 
Borba, H., A. Giampietro-Ganeco, R. A. Souza, J. L. M. Mello, A. B. B. Rodrigues, C. L. Silva, H. Cunali \& T. T. Diniz, 2013. Color, $\mathrm{pH}$ and water activity evaluation of poultry meat from different creations poultry meat. In: Proceedings of the $59^{\text {th }}$ International Congress of Meat Science and Technology, 18-23 August 2013, Izmir, Turkey. http://icomst2013.org/t/e-book/papers/poster/S10A-39.pdf (23 August 2013, date last assessed).

Bosworth, B. G., B. C. Small, D. Gregory, J. Kim, S. Black, \& A. Jerrett, 2007. Effects of rested-harvest using the anesthetic AQUI-STM on channel catfish, Ictalurus punctatus, physiology and fillet quality. Aquaculture, 262, 302-318.

EN 15886, September 2010. Conservation of cultural property - Test methods - Colour measurement of surfaces. European Committee for Standartization. http://www. efsa.europa. eu/en/efsajournal/doc/1013. pdf (27 April 2009, date last assessed).

Erikson, U., L. Hultmann \& J. E. Steen, 2006. Live chilling of Atlantic salmon (Salmo salar) combined with mild carbon dioxide anaesthesia. I. Establishing a method for large-scale processing of farmed fish. Aquaculture, 252, 183-198.

Erikson, U., 2011. Assessment of different stunning methods and recovery of farmed Atlantic salmon (Salmo salar): Isoeugenol, nitrogen and three levels of carbon dioxide. Animal welfare, 20, 365-375.

Erikson, U., B. Lambooij, H. Digre, H. G. M. Reimert, M. Bondø \& H. van der Vis, 2012. Conditions for instant electrical stunning of farmed Atlantic cod after dewatering, maintenance of unconsciousness, effects of stress, and fillet quality - A comparison with AQUI-S ${ }^{\mathrm{TM}}$. Aquaculture, 324-325, 135-144.

Kiessling, A., M. Espe, K. Ruohonen \& T. Mørkøre, 2004. Texture, gaping and colour of fresh and frozen Atlantic salmon flesh as affected by pre-slaughter isoeugenol or $\mathrm{CO}_{2}$ anaesthesia. Aquaculture, 236, 645-657.
Lambooij, E., E. Grimsbø, J. W. van de Vis, H. G. M. Reimert, R. Nortvedt \& B. Roth, 2010. Percussion and electrical stunning of Atlantic salmon (Salmo salar) after dewatering and subsequent effect on brain and heart activities. Aquaculture, 300, 107112.

Llonch, P., E. Lambooij, H. G. M. Reimert, J. W. van de Vis, 2012. Assessing effectiveness of electrical stunning and chilling in ice water of farmed yellowtail kingfish, common sole and pike-perch. Aquaculture, 364-365, 143-149.

Mathlouthi, M., 2001. Water content, water activity, water structure and the stability of foodstuffs. Food Control, 12, 409-417.

Pietrzak, M., M. L. Greaser \& A. A. Sosnicki, 1997. Effect of rapid rigor mortis processes on protein functionality in pectoralis major muscle of domestic turkeys. Journal of Animal Science, 75, 2106-2116.

Rahmanifarah, K., B. Shabanpour, A. Sattari, A. Shabani \& M. R. Imanpour, 2010. Physiological and metabolic responses of common carp (Cyprinus carpio) to different pre-slaughter stunning methods. Africa Journal of Animal and Biomedical Sciences, 5, 21-28.

Rahmanifarah, K., B. Shabanpour \& A. Sattari, 2011. Effects of clove oil on behavior and flesh quality of common carp (Cyprinus carpio L.) in comparison with preslaughter $\mathrm{CO}_{2}$ stunning, chilling and asphyxia. Turkish Journal of Fisheries and Aquatic Sciences, 11, 139-147.

Ribas, L., R. Flos, L. Reig, S. Mackenzie, B. A. Barton \& L. Tort. 2007. Comparison of methods for anaesthetizing Senegal sole (Solea senegalensis) before slaughter: Stress responses and final product quality. Aquaculture, 269, 250-258.

Robb, D. H. F., S. C. Kestin \& P. D. Warriss, 2000. Muscle activity at slaughter: I. Changes in flesh colour and gaping in rainbow trout. Aquaculture, 182, 261-269.

Robb, D. H. F, M. O. Callaghan, J. A. Lines \& S. C. Kestin, 2002. Electrical stunning of rainbow trout (Oncorhynchus mykiss): 
Effect of two stunning methods on postmortem muscle $\mathrm{pH}$ and meat quality of common carp ...

Factors that affect stun duration. Aquaculture, 205, 359-371.

Roth, B., A. Imsland, D. Moeller \& E. Slinde, 2003. Effect of electric field strength and current duration on stunning and injuries in market-sized Atlantic salmon held in seawater. North American Journal of Aquaculture, 65, 8-13.

Roth, B., E. Slinde \& J. Arildsen, 2006. Pre or post mortem muscle activity in Atlantic salmon (Salmo salar). The effect on rigor mortis and the physical properties of flesh. Aquaculture, 257, 504-510.

Roth, B., A. Imsland, S. Gunnarsson, A. Foss \& R. Shelvis-Smit, 2007. Slaughter quality and rigor contraction in farmed turbot (Scophthalmus maximus): A comparison between different stunning methods. Aquaculture, 272, 754-761.

Troller, J. A., 1971. Effect of water activity on enterotoxin B production and growth of Staphylococcus aureus. Applied Microbiology, 21, 435-439.
Wilkinson, R. J., N. Paton \& M. J. R. Porter, 2008. The effects of pre-harvest stress and harvest method on the stress response, rigor onset, muscle $\mathrm{pH}$ and drip loss in barramundi (Lates calcarifer). Aquaculture, 282, 26-32.

Paper received 01.04.2014; accepted for publication 13.06.2014

\section{Correspondence:}

Aleksandra Daskalova, $\mathrm{PhD}$ student Department of Food Hygiene, Technology and Control, Veterinary Legislation and Management,

Faculty of Veterinary Medicine, Trakia University, 6000 Stara Zagora, Bulgaria e-mail: alex_doko@abv.bg 